\title{
Níveis de proteína e fósforo em rações com fitase para frangos de corte, na fase de 14 a 21 dias de idade. 2 . Valores energéticos e digestibilidade de nutrientes ${ }^{1}$
}

\section{Yolanda Lopes da Silva ${ }^{2 *}$, Paulo Borges Rodrigues ${ }^{3}$, Rilke Tadeu Fonseca de Freitas ${ }^{3}$, Márcio Gilberto Zangeronimo ${ }^{2}$, Elias Tadeu Fialho ${ }^{3}$}

\author{
${ }^{1}$ Projeto financiado pelo CNPq. \\ 2 Programa de Pós-Graduação em Zootecnia - UFLA, Lavras, MG. \\ ${ }^{3}$ Departamento de Zootecnia da UFLA - Lavras, MG.
}

RESUMO - Um ensaio de digestibilidade foi conduzido para determinar a energia metabolizável (EMAn), os coeficientes de digestibilidade da matéria seca - MS (CDMS), a excreção e os coeficientes de retenção aparente do fósforo (P), nitrogênio $(\mathrm{N})$, cálcio $(\mathrm{Ca})$, potássio $(\mathrm{K})$, cobre $(\mathrm{Cu})$ e zinco $(\mathrm{Zn})$. Duzentos e cinqüenta pintos de corte, machos, foram distribuídos em um esquema fatorial $3 \times 3+1$ (três níveis de fósforo disponível - 0,25; 0,34 e 0,45\%, três níveis de proteína bruta (PB) - 15,0; 17,0 e 19,0\% e uma ração controle com níveis nutricionais normais), com cinco repetições de cinco aves cada. Às rações com níveis reduzidos de fósforo disponível (Pd) foram adicionadas 500 FTU de fitase, reduzindo-se o teor de Ca em 17\%. Com exceção da ração controle, as demais foram formuladas com base em aminoácidos digestíveis. Os valores energéticos das rações com 15 e 17\% de PB, independentemente dos níveis de Pd utilizados ou da suplementação com a fitase, apresentaram maior EMAn que a ração controle, possivelmente devido à adição de aminoácidos suplementares. Os CDMS das rações com teores de proteína reduzidos e diferentes níveis de Pd foram superiores ao da ração controle. A redução da proteína na ração, associada a baixos níveis de Pd e suplementação com a enzima fitase, permitiu reduzir a excreção de minerais, que tiveram os melhores coeficientes de retenção, com exceção do Zn, que apresentou coeficiente de retenção inferior ao da ração controle. Porém, a excreção de todos os minerais estudados, comparada relativamente ao tratamento controle, foi minimizada quando foram utilizados níveis baixos de PB e do Pd na ração, suplementada com fitase. A manipulação dos níveis de proteína e P em rações suplementadas com aminoácidos e fitase pode reduzir, principalmente, a excreção de $\mathrm{P}, \mathrm{N}$ e $\mathrm{Cu}$, minimizando a poluição ambiental causada por esses elementos.

Palavras-chave: aminoácidos digestíveis, enzima, fósforo disponível, poluição ambiental, proteína ideal

\section{Protein and phosphorus levels in diets with phytase for broilers chicken from 14 to 21 days-old. Energy values and nutrient digestibility}

\begin{abstract}
A digestibility assay was carried out to determine the apparent metabolizable energy values (AMEn), dry matter digestibility coefficients (DMDC), the excretion and apparent retention coefficient of phosphorus (P), nitrogen (N), calcium (Ca), potassium $(\mathrm{K})$, copper $(\mathrm{Cu})$ and zinc $(\mathrm{Zn})$, using 250 Cobb male broiler chickens receiving the treatments distributed in a factorial schedule $3 \times 3+1$ (available phosphorus level $-0.25 ; 0.34$ and $0.45 \%$ and crude protein level [CP]15.0; 17.0 and $19.0 \%$ and a control diet, with normal nutritional levels), with five replicates of five birds each. In the diets with reduced levels of available phosphorus (aP), 500 FTU of phytase were added and calcium requirement was reduced in $17 \%$. Except for control treatment, all the diets were formulated on digestible amino acids basis. The energetic values of the diets with 15.0 and $17.0 \% \mathrm{CP}$, independently of the aP levels used or the phytase supplementation, presented higher AMEn that the control diet possibility regarding to supplemental amino acids addition. The DMDC of the diets with reduced CP levels and different levels of aP were higher than the control diet. The CP reduction in the diet associated to lower aP levels and phytase enzyme supplementation allowed to reduce the minerals excretion, which showed better retention coefficients, except for Zinc that presented lower retention coefficient than the the control diet. However, all minerals excretion, as relatively compared to the control diet, was minimized when lower levels of CP and aP was used in the diet, supplemented with phytase. The manipulation of the protein and phosphorus levels in diets supplemented with amino acids and phytase could reduce mainly the excretion of nitrogen, $\mathrm{P}$ and $\mathrm{Cu}$, minimizing the environment pollution caused by these elements.
\end{abstract}

Key Words: available phosphorus, digestible amino acids, environmental pollution, enzyme, ideal protein

Este artigo foi recebido em 10/8/2006 e aprovado em 11/9/2007. Correspondências devem ser enviadas para pborges@ufla.br.

*Centro de Ciências Agrárias - Curso de Zootecnia - UNIOESTE - Campus Marechal Cândido Rondon, PR. 


\section{Introdução}

Nos modernos sistemas de produção de frangos de corte, é essencial o manejo adequado da cama, para evitar a contaminação dos solos e da água por elementos poluentes como nitrogênio $(\mathrm{N})$, fósforo $(\mathrm{P})$, cobre $(\mathrm{Cu})$ e zinco $(\mathrm{Zn})$, presentes em teores elevados nas excreções das aves. Isto se deve, principalmente, à ineficiência dos animais em utilizar os nutrientes da ração (Cauwenberghe \& Burnham, 2001).

Para melhorar a eficiência de utilização dos nutrientes das rações e, conseqüentemente, reduzir a excreção de elementos poluentes pelas aves, têm sido utilizadas medidas que melhorem a qualidade das rações, como redução dos teores de proteína bruta (PB) e fósforo disponível (Pd) e suplementação com fitase.

Diversos trabalhos mostram que a redução do teor de PB da ração tem possibilitado diminuir a excreção de N. Blair et al. (1999), testando vários programas alimentares, mostraram que as aves alimentadas com rações contendo 25 e 21\% PB nas fases inicial e de crescimento, respectivamente, excretaram $27 \%$ mais $\mathrm{N}$ que o grupo de aves que recebeu rações com 21 e $18 \%$ PB, suplementadas com metionina + cistina, lisina, treonina e triptofano, nestas mesmas fases. Por outro lado, a adição de fitase nas rações de aves também tem se mostrado eficiente em melhorar o aproveitamento do P presente nos alimentos de origem vegetal (Conte et al., 2002), além de poder aumentar os valores energéticos das rações e, conseqüentemente, o aproveitamento de outros nutrientes, como proteínas, aminoácidos, Zn e Cu (Namkung \& Leeson, 1999; Conte et al., 2002).

Camden et al. (2001) observaram que a adição de fitase em rações com níveis reduzidos de Pd e Ca para frangos de corte na fase inicial melhorou a retenção de $\mathrm{N}$ e P, reduzindo esses elementos acumulados no esterco. Semelhantemente, Viveros et al. (2002) verificaram que a suplementação com fitase em rações com nível reduzido de Pd para frangos de corte, nesta mesma fase, aumentou a retenção de $\mathrm{Ca}, \mathrm{P}, \mathrm{Mg}$ e Zn.

O objetivo neste trabalho foi avaliar o efeito da redução dos níveis de proteína e de $\mathrm{P}$ em rações com fitase para frangos de corte na fase inicial, sobre os valores de energia metabolizável aparente corrigida (EMAn), de digestibilidade de matéria seca (MS), de excreção e de coeficiente de retenção aparente de $\mathrm{P}, \mathrm{N}$, Ca, potássio (K), Cu e Zn.

\section{Material e Métodos}

O experimento foi conduzido no Setor de Avicultura do Departamento de Zootecnia da Universidade Federal de Lavras, em Lavras, MG. Duzentas e cinqüenta pintos de corte machos, Cobb, com um dia de vida, foram mantidos em boxes de alvenaria com piso coberto com maravalha até os 14 dias de vida, onde receberam as rações experimentais. O delineamento experimental utilizado foi o inteiramente ao acaso, em esquema fatorial $3 \times 3+1$, sendo três níveis de Pd (0,25; 0,34 e 0,45\%), três níveis de PB (15; 17 e 19\%) e um tratamento adicional, constituído por uma ração controle formulada de acordo com os níveis nutricionais recomendados por Rostagno et al. (2000), totalizando dez tratamentos e cinco repetições de cinco aves cada (Tabelas 1 e 2). Após este período, os grupos de aves foram transferidos e distribuídos aleatoriamente em baterias metálicas, em sala de metabolismo com ambiente controlado, recebendo luz artificial por 24 horas.

As rações experimentais consistiram de milho e farelo de soja, formuladas com base em aminoácidos digestíveis, mantendo-se a relação ideal dos aminoácidos com a lisina. Nas rações com menores níveis de Pd (0,25 e 0,34\%), foram adicionados $500 \mathrm{FTU}$ de fitase/kg (Ronozyme - $2500 \mathrm{FTU} / \mathrm{g}$ ) e reduzido o teor de Ca em $17 \%$.

As rações e a água foram fornecidas à vontade durante todo o período experimental, que compreendeu um período de cinco dias de adaptação das aves às gaiolas e de três dias para a coleta das excretas, utilizando-se a metodologia de coleta total, segundo Rodrigues et al. (2005).

Foram avaliados os valores de energia metabolizável aparente corrigida (EMAn) na MS e o coeficiente de digestitilidade de MS (CDMS) das rações; o consumo, a excreção e os coeficientes de retenção de P, Ca, N, K, Cu e Zn.

As análises estatísticas foram desenvolvidas por intermédio do programa estatístico SAEG versão 5.0 (Euclydes, 1993). Uma análise global com todos os tratamentos foi realizada com o objetivo de obter o quadrado médio do resíduo para testar o fatorial e realizar o teste Dunnet a 5\% com o tratamento adicional. Para a comparação dos tratamentos no esquema fatorial, utilizou-se o teste StudentNewman-Keuls (SNK), a 5\% de probabilidade.

Como algumas rações foram suplementadas com a enzima fitase e outras não, entendeu-se que os tratamentos

Tabela 1 - Composição nutricional dos ingredientes utilizados nas rações experimentais

\begin{tabular}{lcccc}
\hline Ingrediente & MS & PB & Ca & P \\
\hline Milho $^{1}$ & 88,93 & 8,54 & 0,02 & 0,21 \\
Farelo de soja $^{1}$ & 89,81 & 46,02 & 0,30 & 0,63 \\
Fosfato bicálcico & & & $22,044^{1}$ & $18,87^{2}$ \\
Calcário & & $38,86^{2}$ & \\
\hline
\end{tabular}

${ }^{1}$ Valores determinados no Laboratório de Pesquisa Animal da UFLA.

${ }^{2}$ Valores determinados no Laboratório de Fertilizantes e Corretivos da UFLA. 
Tabela 2 - Composição percentual das rações experimentais

\begin{tabular}{|c|c|c|c|c|}
\hline \multirow{3}{*}{$\begin{array}{l}\text { Item } \\
\text { Ingrediente (kg) }\end{array}$} & \multicolumn{4}{|c|}{ Nível de PB (\%) } \\
\hline & \multicolumn{4}{|c|}{ Nível de Pd (\%) } \\
\hline & 0,45 & $0,25 / 0,34 / 0,45$ & $0,25 / 0,34 / 0,45$ & $0,25 / 0,34 / 0,45$ \\
\hline Milho & 56,60 & 72,76 & 67,20 & 61,70 \\
\hline Farelo de soja & 35,7 & 19,10 & 24,50 & 29,20 \\
\hline Calcário calcítico & 1,04 & $1,38 / 1,07 / 1,12$ & $1,38 / 1,07 / 1,12$ & $1,33 / 1,04 / 1,09$ \\
\hline L-lisina & 0,17 & 0,65 & 0,50 & 0,35 \\
\hline DL-metionina & 0,23 & 0,37 & 0,33 & 0,28 \\
\hline L-valina & - & 0,28 & 0,20 & 0,10 \\
\hline L-arginina & - & 0,30 & 0,16 & - \\
\hline L-treonina & - & 0,14 & 0,08 & - \\
\hline Premix mineral $^{2}$ & 0,1 & 0,1 & 0,1 & 0,1 \\
\hline Premix vitamínico ${ }^{3}$ & 0,1 & 0,1 & 0,1 & 0,1 \\
\hline Colina & 0,05 & 0,05 & 0,05 & 0,05 \\
\hline Anticoccidiano $^{1}$ & 0,05 & 0,05 & 0,05 & 0,05 \\
\hline ВНT & 0,01 & 0,01 & 0,01 & 0,01 \\
\hline Fitase & - & $0,02 / 0,02 /$ - & $0,02 / 0,02 /-$ & $0,02 / 0,02 /-$ \\
\hline Caulim & 0,42 & $1,88 / 1,63 / 0,99$ & $1,96 / 1,77 / 1,13$ & $2,02 / 1,81 / 1,17$ \\
\hline Total & 100 & 100 & 100 & 100 \\
\hline \multicolumn{5}{|c|}{ Composição nutricional } \\
\hline PB (\%) & 21,4 & 15 & 17 & 19 \\
\hline EM (kcal/kg) & 3000 & 3000 & 3000 & 3000 \\
\hline Triptofano & 0,24 & 0,17 & 0,18 & 0,21 \\
\hline Fenilalanina & 0,95 & 0,74 & 0,76 & 0,85 \\
\hline
\end{tabular}

1 Princípio ativo maduramicina.

2 Fornecimento por kg de ração: 50 mg Zn; 20 mg Fe; 4 mg Cu; 0,2 mg Co; 75 mg Mn; 1,5 mg I; veículo q.S.p (g) 1.000.

${ }^{3}$ Fornecimento por kg de ração: 6 mg vit. B2; 12.000 Ul vit. A; 2.200 Ul vit D3; 53 mg niacina; 2,2 mg vit.B1; 3,3 mg vit. B6; 16 mcg vit. B12; 0,11mg biotina; $1,0 \mathrm{mg}$ ácido fólico; $130 \mathrm{mg}$ ácido pantotênico $2,5 \mathrm{mg}$ Vit. K3; $30 \mathrm{mg}$ vit. E; 120 mg antioxidante.

ficaram constituídos de combinação nutricional, tornando-se qualitativos, não sendo, portanto, interesse deste trabalho aplicação da regressão polinomial.

\section{Resultados e Discussão}

Os valores obtidos para energia metabolizável aparente corrigida (EMAn) foram superiores $(P<0,05)$ nas rações com 15 e 17\% PB em todos os níveis de Pd estudados, em relação ao tratamento controle (sem redução do nível de PB e com $0,45 \%$ Pd). Isto sugere que a suplementação de rações com fitase e aminoácidos sintéticos permite a redução dos níveis nutricionais de $\mathrm{PB}$, Pd e Ca, além de melhorar os índices energéticos da ração. De acordo com Harms \&
Russel (1998), apenas a suplementação das rações com aminoácidos sintéticos para frangos de corte pode aumentar estes valores obtidos para EMAn (Tabela 3).

Para o coeficiente de digestibilidade de MS (CDMS), constatou-se que as rações com teores de PB reduzidos apresentaram valores superiores $(P<0,05)$ em relação ao tratamento controle, independentemente do nível de Pd estudado. Isto pode ser atribuído ao fato de que a própria redução da PB e suplementação com aminoácidos permite melhor aproveitamento destes nutrientes, os quais são absorvidos com melhor eficiência quando provenientes da proteína dietética. Os resultados indicaram melhora em torno de 8,3\% no CDMS quando se reduziu a PB de 21 para 15\%, independentemente da adição de fitase. Entretanto, 
Tabela 3 - Valores de energia metabolizável aparente corrigida (EMAn) na MS e coeficiente de digestibilidade (CD) de MS de rações com teores de PB e Pd reduzidos suplementadas com aminoácidos e fitase, para frangos de corte na fase de 1 a 21 dias de idade ${ }^{1}$

\begin{tabular}{|c|c|c|c|c|c|}
\hline \multirow[t]{2}{*}{ Item } & \multirow[t]{2}{*}{ Nível PB (\%) } & \multicolumn{4}{|c|}{ Nível de Pd (\%) } \\
\hline & & $\begin{array}{l}0,25+ \\
\text { fitase }\end{array}$ & $\begin{array}{l}0,34+ \\
\text { fitase }\end{array}$ & $\begin{array}{c}0,45 \\
\text { s/fitase }\end{array}$ & Média \\
\hline \multirow{6}{*}{$\begin{array}{l}\text { EMAn } \\
\text { (kcal/kg) }\end{array}$} & 15 & $3.490 *$ & $3.482 *$ & $3.402 *$ & $3.458 \mathrm{a}$ \\
\hline & 17 & $3.398 *$ & $3.348 *$ & $3.390 *$ & $3.378 \mathrm{~b}$ \\
\hline & 19 & 3.323 & 3.270 & 3.295 & $3.296 \mathrm{c}$ \\
\hline & Média & 3.403 & 3.367 & 3.362 & \\
\hline & Controle & & & 3.245 & \\
\hline & CV (\%) & & & 1,56 & \\
\hline \multirow{6}{*}{ CDMS (\%) } & 15 & $78,67 *$ & $78,96^{*}$ & $77,81 *$ & $78,48 \mathrm{a}$ \\
\hline & 17 & $77,05^{*}$ & $77,25 *$ & $76,49 *$ & $76,93 \mathrm{~b}$ \\
\hline & 19 & $74,88^{*}$ & $74,67 *$ & $74,54 *$ & $74,70 \mathrm{c}$ \\
\hline & Média & 76,87 & 76,96 & 76,28 & \\
\hline & Controle & & & 71,86 & \\
\hline & CV (\%) & & & 1,43 & \\
\hline
\end{tabular}

* Médias diferem $(\mathrm{P}<0,05)$ do tratamento controle, pelo teste Dunnet.

${ }^{1}$ Médias seguidas por diferentes letras na coluna diferem $(P<0,05)$ pelo teste SNK.

resultados controversos foram obtidos por Yi et al. (1996a), que constataram, em perus, que a adição dessa enzima em dietas com Pd reduzido (0,45\%) aumentou a utilização da MS nos níveis de PB de 22,5 e 28\%.

A comparação entre as médias dos tratamentos no esquema fatorial mostrou que não houve interação significativa $(\mathrm{P}>0,05)$ para a EMAn e CDMS, porém, foi constatado efeito do nível de PB para ambas as variáveis, observando-se os maiores valores para a ração com 15\% de PB. Este resultado, possivelmente, se deve à maior quantidade de aminoácidos sintéticos adicionados a essa ração.

Também não houve efeito do nível de Pd e fitase sobre os valores de EMAn e CDMS, semelhantemente aos resultados obtidos por Ibrahim et al. (1999). De acordo com Camden et al. (2001), a adição de fitase em dietas de frangos de corte na fase inicial deveria melhorar os valores de EMAn.

Houve redução no consumo e na excreção de $\mathrm{P}$ das aves $(\mathrm{P}<0,05)$ que consumiram as rações com níveis de $\mathrm{PB}$ e Pd reduzidos em relação àquelas alimentadas com a ração controle. Resultados semelhantes foram obtidos por Jacobb et al. (2000), trabalhando nestas mesmas condições, adicionando enzimas às rações (Tabela 4).

Para o coeficiente de retenção do P, a redução de PB da dieta suplementada com aminoácidos e fitase foi eficiente $(\mathrm{P}<0,05)$ em relação ao tratamento controle, exceto quando as rações com 15\% PB e 0,25\% de Pd ou com 19\% PB e
0,34\% Pd foram comparadas. As rações que não foram suplementadas com fitase foram semelhantes ao tratamento controle, demonstrando que a redução da PB das rações e a suplementação com aminoácidos por si só não são eficientes em aumentar a retenção de P pelas aves. Neste caso, a fitase foi fundamental para a melhoria deste parâmetro. O grupo de animais alimentados com rações contendo $17 \%$ de PB e $0,34 \%$ de Pd apresentou melhora de $20,0 \%$ no coeficiente de retenção em relação ao tratamento controle e, de certa forma, redução de mais de $50 \%$ na excreção absoluta de P (Tabela 4).

Ao comparar as médias no fatorial, observou-se interação significativa $(\mathrm{P}<0,05)$ níveis de $\mathrm{PB} \times \mathrm{Pd}$ das rações sobre o consumo e coeficiente de retenção do P. No desdobramento da interação, o consumo de $\mathrm{P}$ foi menor para as aves que consumiram as rações com $\mathrm{PB}$ e $\mathrm{Pd}$ reduzidos, o que já era esperado. Houve aumento $(\mathrm{P}<0,05)$ no coeficiente de retenção deste mineral em dietas com $15 \%$ de PB e $0,34 \%$ de Pd. Por outro lado, em rações com 17 e 19\% de PB, a fitase melhorou o coeficiente de retenção do $\mathrm{P}$ das rações apenas quando os níveis de Pd foram de $0,25 \%$, acima do qual não houve efeito da adição da enzima nesta variável. Isto ocorreu provavelmente porque, nas rações com 17 e 19\% de PB e 0,34\% de Pd, a liberação de $\mathrm{P}$ do fitato pela fitase e o maior teor desse elemento na ração resultaram em aumento na quantidade deste mineral no lúmen intestinal, inibindo sua absorção.

Não houve interação níveis de $\mathrm{PB} \times \mathrm{Pd}$ da ração sobre a excreção de P. Entretanto, houve menor excreção deste mineral $(\mathrm{P}<0,05)$ quando foram utilizadas dietas com $0,25 \%$ de Pd. Este resultado foi similar ao obtido por Yan et al. (2001), que constataram efeitos significativos com níveis reduzidos de Pd em rações suplementadas com fitase.

A redução dos teores de PB e Pd das rações, associada à suplementação ou não com fitase, influenciou significativamente o consumo, a excreção e o coeficiente de retenção de Ca (Tabela 5).

O consumo de Ca foi menor em aves alimentadas com rações contendo 15 e $17 \%$ de $\mathrm{PB}$ e níveis reduzidos de $\mathrm{Pd}$ + fitase em relação àquelas que consumiram a dieta controle. A redução dos níveis dietéticos de PB, Pd e Ca, associada à suplementação de fitase, não diminuiu a excreção de Ca.

Os coeficientes de retenção de Ca das rações com PB e Pd reduzidos, suplementadas com aminoácidos e fitase, foram iguais ou menores que a ração controle. Os menores valores $(\mathrm{P}<0,05)$ de retenção desse mineral foram obtidos com rações contendo 19\% de PB ou 15\% de PB e 0,25\% de $\mathrm{Pd}+$ fitase. Este resultado sugere que a redução da PB e Pd nas rações, mesmo associadas à suplementação com 
Tabela 4 - Consumo, excreção e coeficiente de retenção de fósforo de rações com teores de PB e Pd reduzidos, suplementadas com aminoácidos e fitase para frangos de corte na fase de 1 a 21 dias $^{1}$

\begin{tabular}{|c|c|c|c|c|c|}
\hline \multirow[t]{2}{*}{ Item } & \multirow[t]{2}{*}{ Nível PB (\%) } & \multicolumn{4}{|c|}{ Nível de Pd (\%) } \\
\hline & & $\begin{array}{l}0,25+ \\
\text { fitase }\end{array}$ & $\begin{array}{l}0,34+ \\
\text { fitase }\end{array}$ & $\begin{array}{c}0,45 \\
\text { s/fitase }\end{array}$ & Média \\
\hline \multirow{6}{*}{$\begin{array}{l}\text { Consumo } \\
\text { (mg/ave/dia) }\end{array}$} & 15 & $271 *_{\mathrm{c}}$ & $497 * \mathrm{~b}$ & 681a & 483 \\
\hline & 17 & $310 * \mathrm{c}$ & $432 * b$ & $674 a$ & 472 \\
\hline & 19 & $371 * b$ & $572 \mathrm{a}$ & $561 * a$ & 501 \\
\hline & Média & 317 & 500 & 639 & \\
\hline & Controle & & & 677 & \\
\hline & CV (\%) & 12,20 & & & \\
\hline \multirow{6}{*}{$\begin{array}{l}\text { Excreção } \\
\text { absoluta } \\
\text { (mg/ave/dia) }\end{array}$} & 15 & $98 *$ & $131 *$ & 230 & 153 \\
\hline & 17 & $81 *$ & $145^{*}$ & 253 & 160 \\
\hline & 19 & $107^{*}$ & $207^{*}$ & 244 & 186 \\
\hline & Média & $95 c$ & $161 b$ & $242 \mathrm{a}$ & \\
\hline & Controle & & & 299 & \\
\hline & CV (\%) & 27,04 & & & \\
\hline \multirow{6}{*}{$\begin{array}{l}\text { Coeficiente } \\
\text { retenção (\%) }\end{array}$} & 15 & $64,51 b$ & $73,60 * a$ & $66,31 b$ & 68,14 \\
\hline & 17 & $76,87 * a$ & $66,90 * b$ & $63,03 b$ & 68,93 \\
\hline & 19 & $71,08 * a$ & $63,90 \mathrm{~b}$ & $57,36 b$ & 64,11 \\
\hline & Média & 70,82 & 68,13 & 62,23 & \\
\hline & Controle & & & 55,68 & \\
\hline & CV (\%) & 8,80 & & & \\
\hline Excreção & 15 & 33 & 44 & 77 & \\
\hline relativa aо & 17 & 27 & 48 & 85 & \\
\hline \multirow[t]{2}{*}{ controle (\%) } & 19 & 36 & 69 & 82 & \\
\hline & Controle & & & 100 & \\
\hline
\end{tabular}

* Médias diferem $(P<0,05)$ do tratamento controle, pelo teste Dunnet. Médias seguidas por diferentes letras na mesma linha diferem $(P<0,05)$, pelo teste SNK.

aminoácidos e fitase, não melhora a retenção de Ca. Entretanto, com exceção das aves que consumiram a ração com $19 \%$ de PB e $0,34 \%$ de Pd + fitase, as que consumiram as rações com PB e Pd reduzidos apresentaram redução na excreção relativa de Ca em relação àquelas que receberam a ração controle.

A comparação das médias no fatorial mostrou que houve interação $(\mathrm{P}<0,05)$ níveis de $\mathrm{PB} \times \mathrm{Pd}$ da ração sobre o consumo, a excreção e o coeficiente de retenção do Ca.

As aves alimentadas com as rações contendo teores reduzidos de Pd e Ca em todos os níveis de $\mathrm{PB}$ consumiram menor quantidade de $\mathrm{Ca}$ do que aquelas que receberam as rações com níveis normais de P e Ca. Em todos os níveis de $\mathrm{PB}$, a excreção de Ca foi menor para aves que consumiram rações com níveis reduzidos de $\mathrm{P}$ e Ca suplementadas com fitase, exceto para a ração com $19 \%$ de PB e $0,34 \%$ de Pd + fitase, que apresentou resultado semelhante ao daquelas aves que consumiram as rações sem fitase.
Tabela 5 - Consumo, excreção e coeficiente de retenção de cálcio de rações com teores de PB Pd reduzidos, suplementadas com aminoácidos e fitase, para frangos de corte na fase de 1 a 21 dias

\begin{tabular}{|c|c|c|c|c|c|}
\hline \multirow[t]{2}{*}{ Item } & \multirow[t]{2}{*}{ Nível PB (\%) } & \multicolumn{4}{|c|}{ Nível de Pd (\%) } \\
\hline & & $\begin{array}{l}0,25+ \\
\text { fitase }\end{array}$ & $\begin{array}{l}0,34+ \\
\text { fitase }\end{array}$ & $\begin{array}{c}0,45 \\
\text { s/fitase }\end{array}$ & Média \\
\hline \multirow{6}{*}{$\begin{array}{l}\text { Consumo } \\
\text { (mg/ave/dia) }\end{array}$} & 15 & $655 *^{\mathrm{c}}$ & $814 * b$ & $1.262 \mathrm{a}$ & 910 \\
\hline & 17 & $854 * b$ & $835 * b$ & $1.376 * a$ & 1.022 \\
\hline & 19 & $870 \mathrm{~b}$ & $913 \mathrm{~b}$ & $1.167 \mathrm{a}$ & 983 \\
\hline & Média & 793 & 854 & 1.268 & \\
\hline & Controle & & & 1.081 & \\
\hline & CV (\%) & 12,61 & & & \\
\hline \multirow{6}{*}{$\begin{array}{l}\text { Excreção } \\
\text { absoluta } \\
\text { (mg/ave/dia) }\end{array}$} & 15 & $289 b$ & $287 b$ & $431 \mathrm{a}$ & 336 \\
\hline & 17 & $276 b$ & $282 b$ & $462 * a$ & 340 \\
\hline & 19 & $332 b$ & $423 a$ & $449 * a$ & 401 \\
\hline & Média & 299 & 331 & 447 & \\
\hline & Controle & & & 355 & \\
\hline & CV (\%) & 14,12 & & & \\
\hline \multirow{6}{*}{$\begin{array}{l}\text { Coeficiente } \\
\text { retenção (\%) }\end{array}$} & 15 & $56,24 * b$ & $64,97 a$ & $65,90 \mathrm{a}$ & 62,37 \\
\hline & 17 & 67,76 & 66,32 & 66,24 & 66,77 \\
\hline & 19 & $61,76 * a$ & $55,12 * b$ & $61,54 * a$ & 59,47 \\
\hline & Média & 61,92 & 62,14 & 64,56 & \\
\hline & Controle & & & 67,24 & \\
\hline & CV (\%) & 3,85 & & & \\
\hline \multirow{4}{*}{$\begin{array}{l}\text { Excreção } \\
\text { relativa ao } \\
\text { controle (\%) }\end{array}$} & 15 & 81 & 81 & 121 & \\
\hline & 17 & 78 & 79 & 130 & \\
\hline & 19 & 94 & 119 & 126 & \\
\hline & Controle & & & 100 & \\
\hline
\end{tabular}

* Médias diferem $(P<0,05)$ do tratamento controle, pelo teste Dunnet. Médias seguidas por diferentes letras na mesma linha diferem $(P<0,05)$ pelo teste SNK.

Para o coeficiente de retenção de Ca, a diminuição dos teores de Pd e a suplementação de fitase em rações com teores de PB reduzidos não melhoraram a retenção de $\mathrm{Ca}$, observando-se os menores coeficientes de retenção para a ração com $15 \%$ de PB e $0,25 \%$ de Pd + fitase e ração com $19 \%$ de PB e $0,34 \%$ de Pd + fitase. Este resultado discorda dos obtidos por Viveros et al. (2002), que constataram aumento da retenção de Ca com a suplementação de fitase em rações com níveis reduzidos de $\mathrm{Pd}$.

Os resultados obtidos para o $\mathrm{N}$ (Tabela 6) mostraram que, ao comparar as médias das rações, houve diferenças $(P<0,05)$ para consumo, excreção e coeficiente de retenção deste composto entre as aves que consumiram as rações com PB e Pd reduzidos e a ração controle.

As aves alimentadas com as rações contendo $15 \%$ de PB nos três níveis de Pd e 17\% de PB no nível de 0,25\% de $\mathrm{Pd}+$ fitase ingeriram menos $\mathrm{N}$ que as submetidas à ração controle $(P<0,05)$. Também em relação ao tratamento 
controle, observou-se redução $(\mathrm{P}<0,05)$ na excreção deste elemento em aves que consumiram as rações com PB e Pd reduzidos, independentemente da suplementação de fitase. Este resultado foi similar ao observado por Yi et al. (1996a), que constataram, em perus, que a adição de fitase em dietas com PB e Pd reduzidos diminuiu a excreção de N. Jacobb et al. (2000) também verificaram que a adição apenas de fitase ou combinação de fitase + pentosanase em rações para frangos de corte, com nível reduzido de $\mathrm{PB}$, diminuiu a excreção de $\mathrm{N}$.

O coeficiente de retenção de $\mathrm{N}$ das rações com teores de $\mathrm{PB}$ reduzidos, suplementadas com aminoácidos, independentemente dos teores de Pd e da suplementação de fitase, foi superior ao da ração controle, provavelmente em razão da maior digestibilidade de aminoácidos adicionados nessas rações em relação aos presentes na proteína intacta.

Ao comparar as médias no fatorial, observou-se que houve interação $(\mathrm{P}<0,05)$ níveis de $\mathrm{PB} \times \mathrm{Pd}$, para consumo e excreção de N. No nível de $15 \%$ de PB, o menor consumo foi verificado pelas aves alimentadas com a ração com 0,25\% de Pd + fitase. Nos níveis de 17 e 19\% de PB, não foi observada diferença entre as aves que consumiram as rações com diferentes níveis de Pd. Para $\mathrm{N}$ excretado nos diferentes níveis de PB, a redução do nível de Pd e da suplementação de fitase não teve efeito sobre a diminuição da excreção desse mineral.

Para o coeficiente de retenção de $N$, não houve interação $(\mathrm{P}>0,05)$ níveis de $\mathrm{PB} \times \mathrm{Pd}$, nem foram observados efeitos do nível de PB e Pd da ração. Os resultados obtidos para o efeito da adição de fitase em rações com Pd reduzido sobre a retenção de $\mathrm{N}$ foram semelhantes aos de Ibrahim et al. (1999), que constataram que a utilização de $\mathrm{N}$ por frangos de corte na fase inicial não parece ser melhorada pela suplementação de fitase. Entretanto, foram diferentes dos obtidos por Camden et al. (2001), que constataram que a retenção aparente de $\mathrm{N}$ em frangos de corte aumentou com a adição de fitase em rações com níveis de Pd e Ca reduzidos.

$\mathrm{O}$ consumo de $\mathrm{K}$ das aves alimentadas com a ração controle foi maior $(\mathrm{P}<0,05)$ que o daquelas que receberam as rações com níveis de PB de 15 e 17\% nos três níveis de Pd e $19 \%$ de PB + 0,45\% de Pd sem fitase. Ainda com relação ao tratamento controle, observou-se redução $(P<0,05)$ na excreção desse mineral pelas aves que consumiram as rações com 15\% de PB nos diferentes níveis de Pd e ração com $17 \%$ de PB e $0,25 \%$ de Pd + fitase (Tabela 7).

A comparação das médias das rações no fatorial mostrou que não houve interação $(\mathrm{P}>0,05)$ níveis de $\mathrm{PB} \times \mathrm{Pd}$ da ração sobre o consumo e a excreção de K. Entretanto, houve efeito do nível de PB sobre estas variáveis, sendo que as aves submetidas a rações com níveis reduzidos de PB (15 e 17\%) apresentaram menor consumo e excreção de K em relação às que consumiram rações com $19 \%$ de PB. Este resultado pode ser atribuído à menor quantidade de farelo de soja nessas rações, visto que este ingrediente é a principal fonte de $\mathrm{K}$ das rações.

Os valores obtidos para o coeficiente de retenção de $\mathrm{K}$ mostraram que, no nível de $15 \%$ de PB, a ração com 0,25\% de Pd + fitase apresentou menor coeficiente de retenção. No nível de $17 \%$ de PB, a ração com $0,25 \%$ de Pd + fitase apresentou maior retenção, ao passo que no de $19 \%$ de PB não foi observado efeito da suplementação de fitase sobre a retenção de $\mathrm{K}$.

Os resultados obtidos, comparando-se as médias das rações experimentais e ração controle, mostraram que houve efeito significativo $(\mathrm{P}<0,05)$ dos níveis de $\mathrm{PB}$ e $\mathrm{Pd}$ da ração, associados à suplementação de aminoácidos e fitase, sobre o consumo, a excreção e o coeficiente de retenção de $\mathrm{Cu}$ (Tabela 8 ).

Verificou-se que a ingestão de $\mathrm{Cu}$ foi menor em aves que receberam rações com PB e Pd reduzidos em relação à ração controle, exceto as que consumiram a ração com $19 \%$ de $\mathrm{PB}$ e $0,34 \%$ de Pd + fitase, as quais apresentaram consumo semelhante em relação ao controle. Com relação à quantidade de Cu excretado, a redução dos teores de PB e Pd das rações suplementadas com aminoácidos e fitase foi eficiente em reduzir a excreção e melhorar a retenção desse mineral quando comparadas ao tratamento controle.

A comparação das médias do fatorial mostrou que não houve interação $(\mathrm{P}>0,05)$ níveis de $\mathrm{PB} \times \mathrm{Pd}$ da ração sobre o consumo de $\mathrm{Cu}$. Contudo, houve efeito dos teores de $\mathrm{PB}$ e Pd da ração, de modo que as aves alimentadas com as rações contendo 15 e $17 \%$ de PB e rações com $0,25 \%$ de $\mathrm{Pd}+$ fitase apresentaram menor ingestão de $\mathrm{Cu}$.

Para a excreção e o coeficiente de retenção do $\mathrm{Cu}$, foi constatada interação significativa $(\mathrm{P}<0,05)$ níveis de $\mathrm{PB} \times \mathrm{Pd}$ das rações. Foi verificado que, em todos os níveis reduzidos de $\mathrm{PB}$, a suplementação com fitase nas rações não foi eficiente em reduzir a excreção e melhorar o coeficiente de retenção do Cu. Este resultado foi similar ao observado por Sebastian et al. (1996), que constataram que a suplementação de fitase em dieta de frangos com Pd reduzido não atingiu o nível de retenção de $\mathrm{Cu}$ da dieta normal. Porém, foram contrários aos resultados de Conte et al. (2002), que observaram aumento na absorção de Cu em dietas para frangos com níveis de Pd reduzidos e suplementação com fitase. Entretanto, neste trabalho, as rações não apresentaram teores de $\mathrm{PB}$ reduzidos e suplementação com aminoácidos. Dessa maneira, acredita-se ser necessário reavaliar as exigências de $\mathrm{Cu}$ ao fornecer 
Tabela 6 - Consumo, excreção e coeficiente de retenção de nitrogênio de rações com teores de PB e Pd reduzidos, suplementadas com aminoácidos e fitase para frangos de corte na fase de 1 a 21 dias

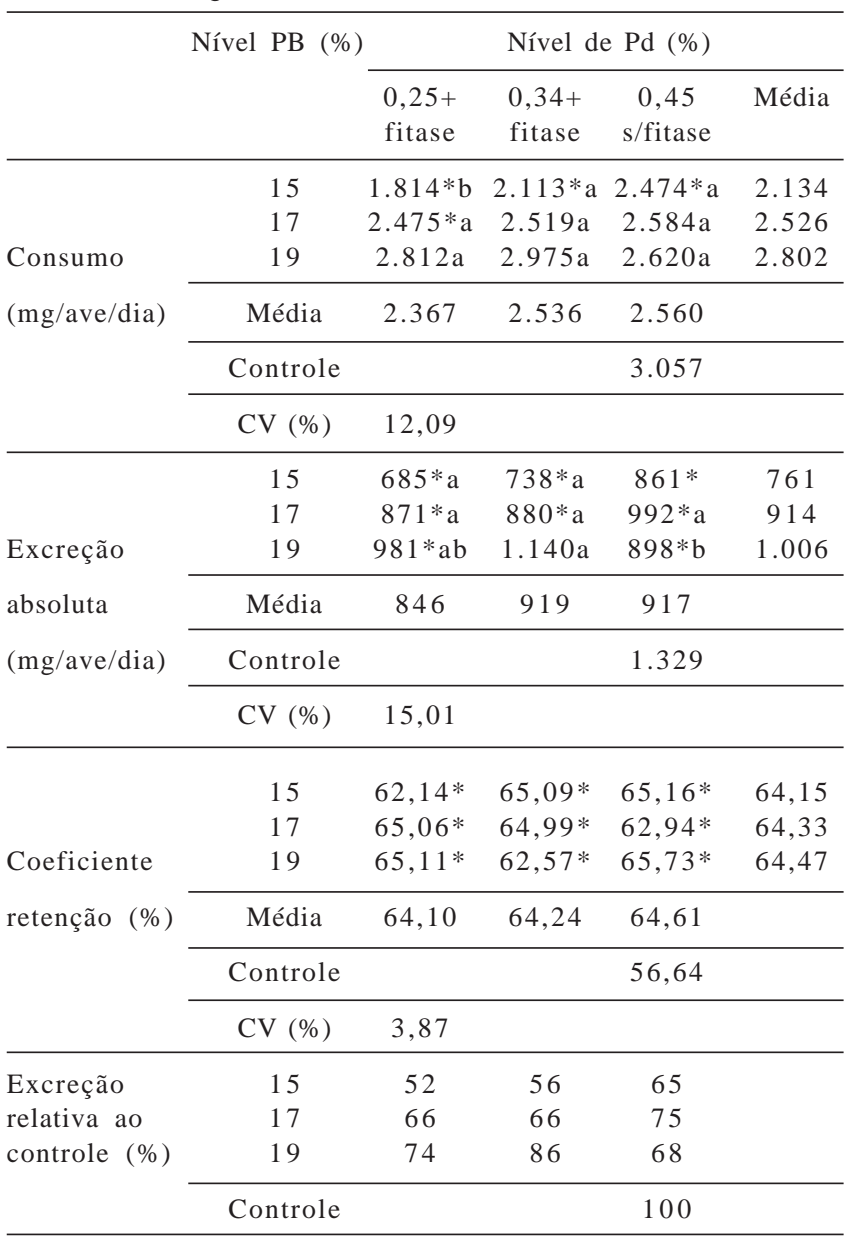

* Médias diferem $(P<0,05)$ do tratamento controle, pelo teste Dunnet. Médias seguidas por diferentes letras na mesma linha diferem $(P<0,05)$, pelo teste SNK.

rações com $\mathrm{PB}$ e $\mathrm{Pd}$ reduzidos e suplementadas com aminoácidos e fitase.

Os teores de PB e Pd das rações influenciaram significativamente $(\mathrm{P}<0,05)$ o consumo, a excreção e o coeficiente de retenção do $\mathrm{Zn}$, comparando a dieta controle em relação às demais. Houve redução no consumo e na excreção de $\mathrm{Zn}$ para as aves que consumiram as rações com PB e Pd reduzidos, independentemente da suplementação de fitase (Tabela 9).

Os coeficientes de retenção de $\mathrm{Zn}$ das rações com 0,45\% de Pd sem fitase, em todos os níveis de PB, foram semelhantes $(\mathrm{P}>0,05)$ ao da ração controle, que foi superior $(\mathrm{P}<0,05)$ aos das demais rações. Isso, possivelmente, decorreu do fato de a fitase liberar Zn do ácido fítico, aumentando sua concentração no intestino e resultando em inibição de sua absorção pelo excesso (Sandströn \&
Tabela 7 - Consumo, excreção e coeficiente de retenção de potássio de rações com teores de PB e Pd reduzidos suplementadas com aminoácidos e fitase, para frangos de corte na fase de 1 a 21 dias

\begin{tabular}{|c|c|c|c|c|c|}
\hline & \multirow[t]{2}{*}{ Nível PB (\%) } & \multicolumn{4}{|c|}{ Nível de Pd (\%) } \\
\hline & & $\begin{array}{l}0,25+ \\
\text { fitase }\end{array}$ & $\begin{array}{l}0,34+ \\
\text { fitase }\end{array}$ & $\begin{array}{c}0,45 \\
\text { s/fitase }\end{array}$ & Média \\
\hline \multirow{6}{*}{$\begin{array}{l}\text { Consumo } \\
\text { (mg/ave/dia) }\end{array}$} & 15 & $480 *$ & $563 *$ & $551 *$ & 531B \\
\hline & 17 & $561 *$ & $541 *$ & $577 *$ & $560 \mathrm{AB}$ \\
\hline & 19 & 614 & 633 & $568 *$ & $605 \mathrm{~A}$ \\
\hline & Média & 552 & 579 & 565 & \\
\hline & Controle & & & 720 & \\
\hline & CV (\%) & 12,29 & & & \\
\hline \multirow{6}{*}{$\begin{array}{l}\text { Excreção } \\
\text { absoluta } \\
\text { (mg/ave/dia) }\end{array}$} & 15 & $310 *$ & $332 *$ & $309 *$ & $317 \mathrm{~B}$ \\
\hline & 17 & $300 *$ & 375 & 373 & 349B \\
\hline & 19 & 410 & 442 & 372 & $408 \mathrm{~A}$ \\
\hline & Média & 340 & 383 & 351 & \\
\hline & Controle & & & 463 & \\
\hline & CV (\%) & 14,30 & & & \\
\hline \multirow{6}{*}{$\begin{array}{l}\text { Coeficiente } \\
\text { retenção (\%) }\end{array}$} & 15 & $35,56 b$ & $41,25 a$ & $43,97 a$ & 40,26 \\
\hline & 17 & $46,41 * a$ & $30,84 b$ & $35,63 b$ & 37,63 \\
\hline & 19 & 33,10 & 29,84 & 34,43 & 32,46 \\
\hline & Média & 38,36 & 33,98 & 38,01 & \\
\hline & Controle & & & 35,80 & \\
\hline & CV (\%) & 12,58 & & & \\
\hline \multirow{4}{*}{$\begin{array}{l}\text { Excreção } \\
\text { relativa ao } \\
\text { controle (\%) }\end{array}$} & 15 & 67 & 72 & 67 & \\
\hline & 17 & 65 & 81 & 81 & \\
\hline & 19 & 89 & 95 & 80 & \\
\hline & Controle & & & 100 & \\
\hline
\end{tabular}

* Médias diferem $(P<0,05)$ do tratamento controle, pelo teste Dunnet. Médias seguidas por diferentes letras (minúscula na linha e maiúscula na coluna) diferem $(P<0,05)$ pelo teste SNK.

Cederblad, 1980, citados por Lönnerdal, 2000). No entanto, os resultados obtidos por Walz \& Pallauf (2002), para suínos em crescimento e terminação, mostraram que a redução da PB e Pd, combinada com a suplementação de aminoácidos e fitase, aumentou a retenção de Zn.

As aves que consumiram as rações com PB reduzida, de modo geral, apresentaram menor $(\mathrm{P}<0,05)$ excreção relativa de $\mathrm{Zn}$ do que aquelas alimentadas com a ração controle.

Ao comparar as médias no fatorial, constatou-se que não houve interação $(\mathrm{P}>0,05)$ níveis de $\mathrm{PB} \times \mathrm{Pd}$ das rações sobre o consumo, a excreção e retenção do Zn. Entretanto, observou-se efeito do nível de PB da ração sobre o consumo e a excreção de $\mathrm{Zn}$, que foram reduzidos em aves que receberam rações com $15 \%$ de $\mathrm{PB}$ em relação às rações com 19\% de PB. Além disso, os teores reduzidos de PB das rações não tiveram efeito significativo $(\mathrm{P}>0,05)$ sobre o coeficiente 
Tabela 8 - Consumo, excreção e coeficiente de retenção de cobre de rações com teores de PB e Pd reduzidos, suplementadas com aminoácidos e fitase, para frangos de corte na fase de 1 a 21 dias

\begin{tabular}{|c|c|c|c|c|c|}
\hline & \multirow[t]{2}{*}{ Nível PB (\%) } & \multicolumn{4}{|c|}{ Nível de Pd (\%) } \\
\hline & & $\begin{array}{l}0,25+ \\
\text { fitase }\end{array}$ & $\begin{array}{l}0,34+ \\
\text { fitase }\end{array}$ & $\begin{array}{c}0,45 \\
\text { s/fitase }\end{array}$ & Média \\
\hline \multirow{6}{*}{$\begin{array}{l}\text { Consumo } \\
\text { (mg/ave/dia) }\end{array}$} & 15 & $0,15 *$ & $0,17 *$ & $0,17 *$ & $0,16 \mathrm{~B}$ \\
\hline & 17 & $0,16 *$ & 0,17 * & $0,19 *$ & $0,17 \mathrm{~B}$ \\
\hline & 19 & $0,18^{*}$ & 0,21 & $0,17 *$ & $0,19 \mathrm{~A}$ \\
\hline & Média & $0,16 b$ & $0,18 \mathrm{a}$ & 0,18 a & \\
\hline & \multicolumn{2}{|l|}{ Controle } & \multicolumn{3}{|c|}{0,24} \\
\hline & CV (\%) & 12,42 & & & \\
\hline \multirow{6}{*}{$\begin{array}{l}\text { Excreção abso } \\
\text { (mg/ave/dia) }\end{array}$} & 15 & $0,07 * a$ & $0,07 * a$ & $0,07 * a$ & 0,07 \\
\hline & 17 & $0,08 * a$ & $0,08 * a$ & $0,10 * a$ & 0,09 \\
\hline & luta 19 & $0,11 * b$ & $0,13 * a$ & $0,09 * b$ & 0,11 \\
\hline & Média & 0,09 & 0,09 & 0,09 & \\
\hline & Controle & & & 0,17 & \\
\hline & CV (\%) & & 14,34 & & \\
\hline \multirow{6}{*}{$\begin{array}{l}\text { Coeficiente } \\
\text { retenção (\%) }\end{array}$} & 15 & $56,04 *$ & $58,55^{*}$ & $56,70 *$ & 57,10 \\
\hline & 17 & $50,08 *$ & $50,73^{*}$ & $47,13 *$ & 49,31 \\
\hline & 19 & $40,41 * b$ & $39,66^{*} \mathrm{~b}$ & $47,35^{*} \mathrm{a}$ & 42,47 \\
\hline & Média & 48,84 & 49,65 & 50,39 & \\
\hline & Controle & & & 27,70 & \\
\hline & CV (\%) & & 6,11 & & \\
\hline \multirow{4}{*}{$\begin{array}{l}\text { Excreção } \\
\text { relativa ao } \\
\text { controle (\%) }\end{array}$} & 15 & 41 & 41 & 41 & \\
\hline & 17 & 47 & 47 & 59 & \\
\hline & 19 & 65 & 76 & 53 & \\
\hline & Controle & & & 100 & \\
\hline
\end{tabular}

*Médias diferem $(P<0,05)$ do tratamento controle, pelo teste Dunnet. Médias seguidas por diferentes letras (minúsculas na mesma linha e maiúsculas na coluna) diferem $(P<0,05)$ pelo teste SNK.

de retenção de Zn. Entretanto, houve efeito dos níveis de Pd e da suplementação de fitase $(\mathrm{P}<0,05)$, tendo a ração com $0,45 \%$ de Pd sem fitase apresentado coeficiente de retenção superior às demais rações, sugerindo ser necessário reavaliar as exigências de Zn na suplementação das rações com fitase. Este resultado foi semelhante ao de Roberson \& Edwards (1994), que verificaram que a adição de fitase na ração não afetou a retenção de Zn. Porém, foram diferentes dos resultados de Sebastian et al. (1996), Yi et al. (1996 b) e Viveros et al. (2002), que constataram que a suplementação de fitase em dietas para frangos de corte com teores de Pd reduzido aumentou a retenção de Zn. Este resultado ser atribuído à maior disponibilidade de $\mathrm{Zn}$ do complexo mineral-fitato, no entanto, as rações não apresentaram teor de PB reduzido e não foram suplementadas com aminoácidos.
Tabela 9 - Consumo, excreção e coeficiente de retenção de zinco de rações com teores de PB e Pd reduzidos e suplementadas com aminoácidos e fitase, para frangos de corte na fase de 1 a 21 dias

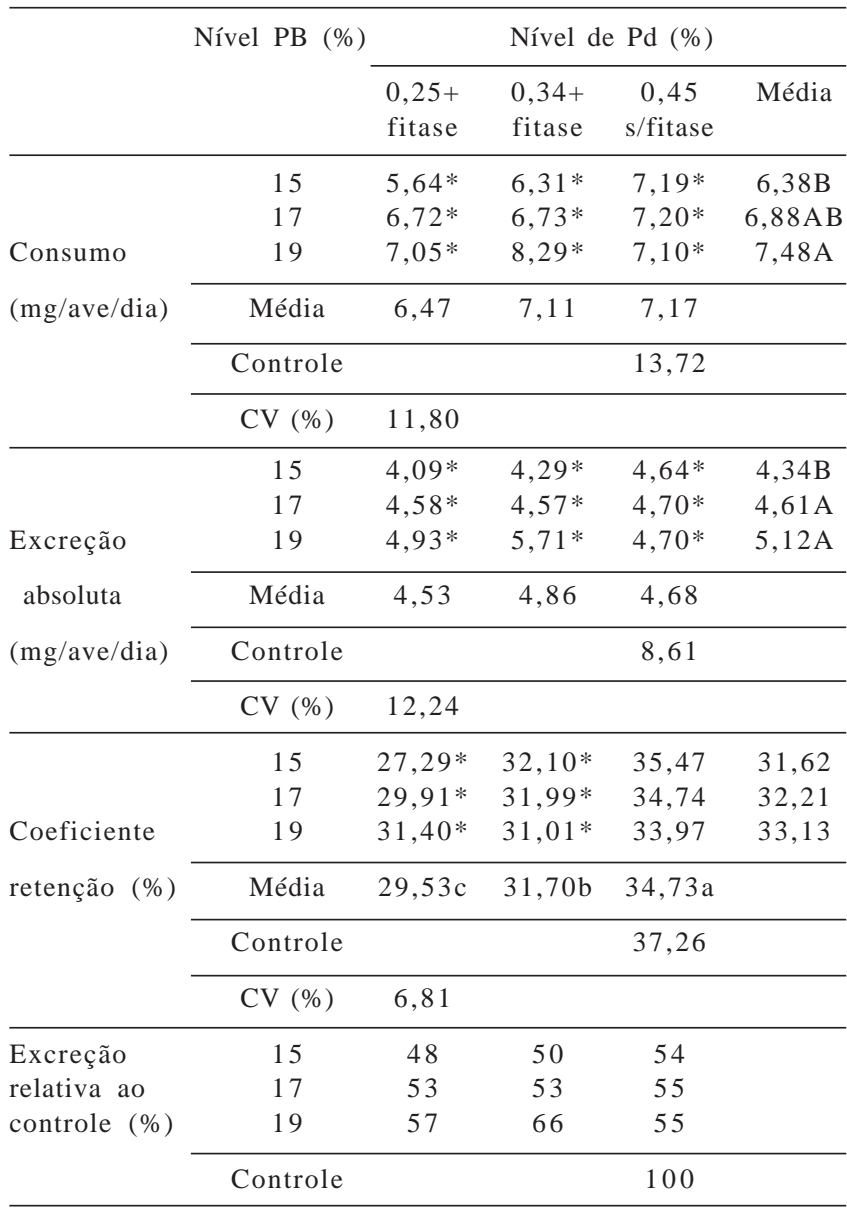

*Médias diferem $(P<0,05)$ do tratamento controle, pelo teste Dunnet. Médias seguidas por diferentes letras (minúsculas na mesma linha e maiúsculas na coluna) diferem $(P<0,05)$ pelo teste SNK.

\section{Conclusões}

A manipulação dos níveis de PB e Pd nas rações de frangos de corte na fase inicial pode melhorar os valores de energia metabolizável aparente corrigida e de digestibilidade de MS das rações, além de interferir na excreção e retenção de minerais pelas aves. Dessa forma, a formulação de rações com aminoácidos sintéticos utilizando o conceito de proteína ideal, associada à adição de fitase, pode reduzir a poluição ambiental causada pela excreção principalmente de N, P e Cu.

\section{Agradecimento}

À Roche Vitaminas do Brasil, pela doação da enzima fitase para a realização dos experimentos. 


\section{Literatura Citada}

BLAIR, R.; JACOB, J.P.; IBRAHIM, S. et al. A quantitative assessment of reduced protein diets and supplements to improve nitrogen utilization. Journal Applied Poultry Research, v.8, n.1, p.25-47, 1999.

CAMDEN, B.J.; MOREL, P.C.H.; THOMAS, D.V. et al. Effectiveness of exogenous microbial phytase in improving the bioavailabilities of phosphorus and other nutrients in maize -soya-bean meal diets for broilers. Animal Science, v.73, n.2, p.289-297, 2001.

CAUWENBERGHE, S.V.; BURNHAM, D. New developments in amino acid protein nutrition of poultry, as related to optimal performance and reduced nitrogen excretion. In: EUROPEAN SYMPOSIUM OF POULTRY NUTRITION, 13., 2001, Blankenberge. Anais... Blankenberge: 2001. não-paginado.

CONTE, A.J.; TEIXEIRA, A.S.; BERTECHINI, A.G. et al. Efeito da fitase e xilanase sobre a energia metabolizável do farelo de arroz integral em frangos de corte. Ciência e Agrotecnologia, v.26, n.6, p.1289-1296, 2002.

EUCLYDES, R.F. Sistema de análises estatísticas e genéticas - versão 5.0: guia do usuário. Viçosa, MG: Central de Processamento de Dados - UFV. 1993. 59p.

HARMS, R.H.; RUSSEL, G.B. Adding methionine and lysine to broiler diets to lower feed costs. Journal of Applied Poultry Research, v.7, n.2, p.202-218, 1998a.

IBRAHIM, S.; JACOB, J.P.; BLAIR, R. Phytase supplementation to reduce phosphorus excretion of broilers. Journal of Applied Poultry Research, v.8, n.4, p.414-425, 1999.

JACOBB, J.P.; IBRAHIM, S.; BLAIR, R. et al. Using enzyme supplemented, reduced protein diets to decrease nitrogen and phosphorus excretion of broilers. Asian Australasian Journal of Animal Sciences, v.13, n.11, p.1561-1567, 2000.

LÖNNERDAL, B. Dietary factors influencing zinc absorption. Journal Nutrition, v.130, p.1378-1383, 2000 (suppl.).

RODRIGUES, P.B.; MARTINEZ, R.S.; FREITAS, R.T.F. et al. Influência do tempo de coleta e metodologias sobre a digestibilidade e o valor energético de rações para aves. Revista Brasileira de Zootecnia, v.34, n.3, p.882-889, 2005.

NAMKUNG, H.; LEESON, S. Effect of phytase enzyme on dietary nitrogen-corrected apparent metabolizable energy and the ileal digestibility of nitrogen and amino acids in broiler chicks Poultry Science, v.78, n.9, p.1317-1319, 1999.

ROBERSON, K.D.; EDWARDS JR., H.M. Effects of 1, 25 dihydroxycholecalciferol and phytase on zinc utilization in broiler chicks. Poultry Science, v.73, n.8, p.1312-1326, 1994.

ROSTAGNO, H.S.; ALBINO, L.F.T.; DONZELE, J.L. et al. Tabelas brasileiras para aves e suínos: composição de alimentos e exigências nutricionais. 2.ed. Viçosa, MG: Universidade Federal de Viçosa, 2000. 141p.

SEBASTIAN, S.; TOUCHBURN, S.P.; CHAVEZ, E.R. et al. The effects of supplemental microbial phytase on the performance and utilization of dietary calcium, phosphorus, copper, and zinc in broiler chickens fed corn-soybean diets. Poultry Science, v.75, n.6, p.729-736, 1996.

VIVEROS, A.; BRENES, A.; ARIJA, I. et al. Effects of microbial phytase supplementation on mineral utilization and serum enzyme activities in broiler chicks fed different levels of phosphorus. Poultry Science, v.81, n.8, p.1172-1183, 2002.

WALZ, O.P.; PALLAUF, J. Microbial phytase combined with amino acid supplementation reduces $\mathrm{P}$ and $\mathrm{N}$ excretion of growing and finishing pigs without loss of performance. International Journal of Food Science and Technology, v.37, n.7, p.835848, 2002.

YAN, F.; KERSEY, H.; WALDROUP, P.W. Phosphorus requirements of broiler chicks three to six weeks of age as influenced by phytase supplementation. Poultry Science, v.80, n.4, p.455459, 2001.

YI, Z.; KORNEGAY, E.T.; DENBOW, D.M. Effect of microbial phytase on nitrogen and amino acid digestibility and nitrogen retention of turkey poultry fed corn-soybean meal diets. Poultry Science, v.75, n.8, p.979-990, 1996a.

YI, Z.; KORNEGAY, E.T.; DENBOW, D.M. Supplemental microbial phytase improves zinc utilization in broilers. Poultry Science, v.75, n.4, p.540-546, 1996 b. 